\title{
PENGARUH JUMLAH PEMBELI TERHADAP KEUNTUNGAN PADA TOKO KELONTONG SEBELUM DAN SESUDAH BERDIRINYA MINI MARKET DI KOTA BUNTOK KALIMANTAN TENGAH
}

\author{
The Effect of Buyers Number towards Profits on Grocery Stores Before and After \\ Establishment of Mini Market in Buntok City Central Borneo
}

\author{
Harlina Kuriaty \\ Management Study Program, Dahani Dahanai Institute of Economic Science, Buntok, Indonesia
}

\begin{abstract}
ABSTRAK
Penelitian ini bertujuan untuk mengetahui pengaruh jumlah pembeli terhadap keuntungan pada toko kelontong sebelum dan sesudah berdirinya Mini Market di kota Buntok, Kalimantan Tengah. jenis penelitian ini adalah Penelitian kuantitatif deskriftif. Data yang di gunakan di dapat dari proses Wawancara dan penyebaran kuisioner. Sampel yang dijadikan penelitian ini menggunakan 31 toko kelontong sebagai nara sumber. Analisis yang dilakukan menggunakan skala likert dan analisis regresi sederhana. Berdasarkan hasil penelitian di temukan adanya pengaruh jumlah pembeli terhadap keuntungan pada toko kelontong sebelum dan sesudah berdirinya Mini Market di kota buntok kalimantan tengah. Hal ini dapat dilihat dari hasil regresi linier sederhana sebesar $y=3,601+0,876 x$, terjadi hubungan positif antara jumlah pembeli dengan keuntungan setelah berdirinya Mini Market terhadap toko kelontong, hasil perhitungan koefisien regresi sederhana (uji t) bahwa thitung > t tabel $(17,520>2,048)$ maka $\mathrm{HO}$ ditolak artinya bahwa ada pengaruh jumlah pembeli dengan keuntungan pada toko kelontong setelah berdiri Mini Market.
\end{abstract}

Kata kunci: Jumlah Pembeli, Keuntungan, Toko Kelontong, Minimarket

\begin{abstract}
The study aims to determine the effect of the number of buyers on profits at the grocery store before and after the establishment of Mini Market in the city of Buntok, Central Kalimantan. this type of research is descriptive quantitative research. The data used in the process can be from the interview and the distribution of questionnaires. The sample used in this study used 31 grocery stores as resource persons. The analysis was done using Likert scale and simple regression analysis. Based on the results of research found the influence of the number of buyers to profit on grocery store before and after the establishment of Mini Market in town buntok central kalimantan. It can be seen from the result of simple linear regression equal to $y=3.601+0.876 x$, there is a positive relationship between the number of buyers with profit after the establishment of Mini Market to the grocery store, the calculation result of simple regression coefficient ( $t$ test) that $t$ count $>t$ table $(17.520>2.048)$ then $\mathrm{HO}$ rejected means that there is influence of the number of buyers with profit on the grocery store after the Mini Market stand.
\end{abstract}

Keywords: Buyers Number, Profit, Grocery Store, Mini Market

\section{PENDAHULUAN}

Perkembangan dunia usaha di Indonesia belakangan ini semakin lama semakin meningkat, sehingga semakin menimbulkan dampak persaingan di berbagai sektor usaha. Salah satunya persaingan antara pasar tradisional dan pasar modern.Keberadaan pasar modern di Indonesia mengalami perkembangan yang sangat pesat menurut data penelitian pasar global 2016, hipermarket merupakan peritel dengan tingkat pertumbuhan paling tinggi (25\%), koperasi $(14,2 \%)$, minimarket $(12,5 \%)$, toko penjual bahan makanan yang berdiri sendiri $(8,5 \%)$ dan pasar swalayan $(3,5 \%)$. Selain mengalami pertumbuhan dari sisi jumlah dan angka penjualan, peritel modern mengalami pertumbuhan pangsa pasar sebesar 2,4 persen per tahun terhadap pasar tradisional. Keberadaan pasar modern di 
Indonesia akan berkembang dari tahun ke tahun. Perkembangan yang pesat ini bisa jadi akan terus menekan keberadaan pasar tradisional pada titik terendah dalam 20 tahun mendatang. Pasar modern yang pada kenyataannya dimiliki oleh peritel (pengecer) asing dan konglomerat lokal akan menggantikan peran pasar tradisional seperti pedagang kelontong.

Berdasarkan data rekapitulasi Badan Pusat Statistik Barito Selatan jumlah penduduk untuk tahun 2016 adalah 133.304 juta jiwa. Sedangkan untuk sektor perdagangan di Kabupaten Barito Selatan sebesar 7,57 persen dari jumlah penduduk yang ada. Melihat jumlah penduduk diatas maka para investor dibidang perdagangan khususnya penyedia bahan kebutuhan sehari - hari semakin banyak yang ingin melakukan atau mendirikan usahanya di Kabupaten Barito Selatan. Dengan adanya hal tersebut maka eksistensi warung tradisional maupun kelontong yang berdiri sendiri mengalami penurunan. Selain itu ritel modern mengalami pertumbuhan cukup pesat seperti minimarket karena menggunakan konsep waralaba atau franchise.

Budaya, sejerah, mudah dijangkau, harga bisa ditawar, informasi produk beragam, peluang usaha dan pekerjaan. Pasar plaza beringin sehat, ramah lingkungan, dan indah merupakan konsep pemikiran ulang menuju peningkatan performa pasar tradisional. Konsep ini mengarah pada dua hal yaitu (1) Optimalisasi kenerja pasar tradisional dan peningkatan infrastruktur, (2) Pengembalian peran pasar tradisional sebagai distributor produkproduk lokal upaya tersebut di harapkan mampu menjadi pasar tradisional memenuhi syarat minimal sebuah pasar, dimana terbangun regularity, adequacy, dan security dengan terciptanya comfortability bagi pelaku pasar dalam berniaga.

Beberapa daerah diwilayah indonesia masih sangat tergantung dengan keberadaan pasar tradisional dalam memenuhi kebutuhan penduduknya sehari -hari. Bahkan ada beberapa daerah hanya dapat menghadirkan pasar tradisional Cuma satu minggu satu kali dua kali. Pada pasar tradisional juga terdapat yang namanya toko kelontong. Barang dagangannya pun sangat bervariasi. Pasar ini sering disebut pasar kaget atau bazar mingguan. Biasanya para pedagangnya tidak menjual sayuran mentah atau lauk pauk mentah. Karena target sasaran atau pangsa pasarnya adalah masyarakat menengah keatas yang modern, maka pasar tersebut justru menghadirkan aneka masakan siap saji. Dari aneka lauk pauk, kue-kue, sayuran matang sampai jajaran pasar.

Jenis-jenis pasar tradisional yang terdapat di kota Buntok sendiri adalah sebagai berikut:

1. Pasar subuh

Pasar subuh adalah pasar yang berlokasi di taman iring witu Buntok. Yang mana pasar subuh dimulai pada pukul 02.00 malam sampai pukul 06.00 pagi. Di pasar subuh bermacam jenis barang di jual seperti sayur-sayuran, ikan, sembako dan berbagai macam - macam kue. Begitu banyak pengunjung yang datang kepasar subuh, karena harga yang dijual dipasar subuh sangat mudah dijangkau dan relatif murah dari pasar - pasar yang lain.

2. Pasar trowongan

Pasar trowongan adalah pasar yang terletak di sudut-sudut pasar plaza beringin Buntok, maka itulah di sebut pasar trowongan. pasar trowongan juga tidak beda jauh dengan pasar 
subuh, karena pasar trowongan juga menjual sayur - sayuran, ikan dan sembako. Adapun yang membedakan pasar trowongan dengan pasar subuh, harga barang di pasar trowongan lebih relatif tinggi dibandingkan pasar subuh.

3. Pasar saik

Pasar saik adalah pasar sayur-sayuran dan ikan yang berlokasi di jalan merdeka raya tepat berseberangan dengan pasar plaza beringin dan tidak jauh dari pesisir sungai barito, pengunjungnya pun sangat banyak karena ikan dan sayur - sayurannya pun begitu lengkap.

4. Pasar jelapat

Pasar jelapat adalah pasar yang berlokasi di ujung kota Buntok. Pasar jelapat dimulai pukul 14.00 siang sampai pukul 17.00 sore, yang berlokasi pada ujung kota Buntok Kalimantan Tengah, yang mana pasar jelapat menjual berbagai kebutuhan sehari - hari dari sembako, sayur - sayuran, ikan dan daging.

5. Pasar buah

Pasar buah adalah pasar yang menjual bermacam buah - buahan yang mana pasar buah berlokasi pada plaza beringin Buntok Kalimantan Tengah.

6. Pasar plaza beringin

Pasar plaza beringin adalah pasar yang sering dikunjungi oleh pengunjung di luar kota Buntok maupun di kota Buntok. Karena pasar plaza beringin Buntok pasar yang besar di kota Buntok. Sehingga barang yang dijual sangat begitu banyak seperti sembako, pakaian, emas dan barang - barang yang lain.

\section{METODOLOGI}

Dalam penelitian ini, peneliti menggunakan metodelogi kuantitatif deskriftif. Penelitian ini marupakan penelitian yang menjelaskan gejala yang ada, dengan menggunakan angka - angka untuk menjelaskan karakteristik individu atau kelompok.

\section{HASIL DAN PEMBAHASAN}

Dari hasil jawaban kuesioner yang diberikan kepada 31 responden di toko kelontong yang terdiri dari dua indikator yaitu, jumlah pengunjung dan keuntungan responden diminta memilih salah satu jawaban diantaranya lima pilihan jawaban.

\section{Analisis regresi linier sederhana}

Rumus $=y+b x$, setelah di lakukan perhitungan di peroleh hasil $Y=3,601+0,875 x$ Arti persamaan ini adalah nilai konstanta (a) sebesar 3,601 artinya jika jumlah pembeli ( $x$ ) nilainya adalah 0 maka keuntungan (y) nilainya sebesar 3,601, kemudian koefisen regresi jumlah pembeli $(X)$ sebesar 0,876 artinya jika nilai skor jumlah pembeli mengalami kenaikan sebanyak 1 kali, maka hasil keuntungan (Y) akan mengalami kenaikan sebesar 0,875, serta koefisen bernilai positif artinya terjadi hubungan positif antara jumlah pembeli dengan keuntungan semakin tinggi jumlah pembeli yang dihasilkan maka semakin meningkat jumlah keuntungan. Hal ini dapat dilihat dari banyak nya jumlah pembeli yang berbelanja di toko kelontong dengan Mini Market. Apabila jumlah pembeli lebih banyak ke toko kelontong maka keuntungan yang dihasilkan semakin meningkat. Apabila jumlah pembeli lebih banyak ke mini market maka keuntungan pada toko kelontong semakin menurun

\section{Uji Koefisien Regresi Sederhana (Uji t)}

Rumus thitung pada analisis regresi adalah :

$$
\text { t hitung }=\frac{b}{s b}
$$


Keterangan ;

$\mathrm{b}=$ Koefisien Regresi

$\mathrm{sb}=$ Standar Error

Untuk mencari nilai standar error (Sb) maka harus menemukan nilai standar error (Sxy) terlebih dahulu, seperti dibawah ini :

$$
\begin{aligned}
& \text { sxy }=\sqrt{\frac{\sum_{y} 2-a \sum y-b \sum x y}{n-2}} \\
& \text { Sxy }=\sqrt{\frac{25383-(3,601) \cdot(879)-(0,876) \cdot(25317)}{31-2}} \\
& \text { Sxy }=\sqrt{\frac{25383-3165,279-22177,692}{29}} \\
& \text { Sxy }=\sqrt{\frac{40,029}{29}} \\
& \text { Sxy }=\sqrt{1,380} \\
& \text { Sxy }=1,175
\end{aligned}
$$

Setelah mendapatkan nilai standar error (Sxy), kemudian dilanjutkan ke perhitungan dengan menggunakan rumus sebagai berikut:

$$
\begin{aligned}
\mathrm{Sb} & =\frac{\text { Sxy }}{\sqrt{\left[\mathrm{x}_{\mathrm{x}}^{2}-\left(\sum \mathrm{x}\right)^{2} / \mathrm{n}\right]}} \\
\mathrm{Sb} & =\frac{1,175}{\sqrt{[25300-767376 / 31}} \\
\mathrm{Sb} & =\frac{1,175}{\sqrt{25300-24754,065}} \\
\mathrm{Sb} & =\frac{1,175}{\sqrt{545,935}} \\
\mathrm{Sb} & =\frac{1,175}{23,365} \\
\mathrm{Sb} & =0,05028889
\end{aligned}
$$

Nilai standar error $S_{x y}$ sebesar 1,175 menunjukan nilai $Y$ menyebar dari persamaan regresi sebesar 1,175 Kemudian dari hasil standar error $S_{x y}$ akan dimasukan ke pencarian standar error untuk penduga $b$ yaitu $S_{b}$ sebesar 0,050 . Maka t hitung pada analisis regresi di peroleh sebesar 17,520
Tingkat signifikan 0,05 adalah ukuran standar yang sering digunakan dalam penelitian, jadi dalam menentukan $t$ tabel dicari pada $a=5 \%: 2=2,5 \%$ (uji 2 sisi) dengan derajat kebebasan (df) n-k-1 = 31-2-1= 28 (dimana $n$ adalah jumlah responden dan $\mathrm{k}$ adalah jumlah variabel). Dengan penguji 2 sisi (signifikan $=0.025$ ) hasil diperoleh untuk $t$ tabel sebesar 2,048 Dari pengujian diatas dapat dilihat bahwa $t$ hitung $>t$ tabel $(17,520>2,048$ maka Ho ditolak, artinya bahwa ada pengaruh secara signifikan antara jumlah pembeli dengan keuntungan. Serta digambarkan pada grafik dibawah ini.

\section{KESIMPULAN}

Mengenai pengaruh jumlah pembeli terhadap keuntungan pada toko kelontong sebelum dan sesudah berdirinya mini market di kota buntok. Pemilik toko kelontong di kota buntok harus terus meningkatkan pelayanan dan keramahan kepada pelanggannya dengan baik. Dari hasil penelitian di ketahui bahwa ada pengaruh jumlah pembeli terhadap keuntungan sebelum dan sesudah berdirinya mini market di kota buntok kalimantan tengah. Berdasarkan hasil regresi linier sederhana sebesar $y=3,601+0,876 x$ dimana semakin tinggi nilai jumlah pembeli semakin meningkat keuntungan, dan dengan menguji koefisien regrisi sederhana (uji t) bahwa dari pengujian tersebut $t$ hitung $>\mathrm{t}$ tabel $(17,520>2,048)$ maka Ho ditolak artinya bahwa ada pengaruh jumlah pembeli dengan keuntungan pada toko kelontong. Karyawan pada toko kelontong agar dapat meningkatkan kualitas pelayanan yang lebih baik lagi, hal ini dimaksudkan guna dapat menunjang kepuasan pelanggan. Pihak toko kelontong agar dapat melihat dan mengawasi setiap pekerjaan 
para karyawannya dalam melayani pembeli agar semuanya lebih baik.

\section{DAFTAR PUSTAKA}

Nielsen. 2010. Pasar Modern, Minimarket, Lembaga Risen.

Sadillah. 2011. Eksistensi Pasar Tradisional (Relasi dan Jaringan Pasar Tradisional Dikota Semarang - Jawa Tengah). BPSNT. Yogyakarta.

Sugiyono. 2008. Metode Penelitian Kuantitatif Kualitatif. Bandung, Alfabeta.

Sekaran, U. 2006. Research method for business, Edisi 1 dan 4. Salemba Empat, Jakarta.

Priyanto. 2008. Mandiri belajar SPSS, (statistical product and service solution) untuk analisis data dan uji statisik. Yogyakarta : Mediacom.

Priyanto, D. 2008. Mandiri Belajar SPSS, cetakan ketiga, Yogyakarta : Mediacom. 